\title{
TERS YÜZ SINIF
}

\author{
FLIPPED CLASSROOM
}

\author{
Cüneyt Orhan Kara \\ Pamukkale Üniversitesi Tıp Fakültesi Kulak Burun Boğaz Anabilim Dalı, Denizli, Türkiye \\ e-mail: cokara@yahoo.com \\ DOI:10.5152/tcb.2015.064
}

\section{Özet}

Ters yüz sınıf öğrenciyi merkez alan nispeten yeni bir öğrenme yaklaşımıdır. Bu yöntemde dersler ders saatleri dışında çevrim içi olarak yapılırken, sınıf içinde aktif öğrenme etkinlikleri yapılmaktadır. Öğretmen sınıf içindeki yüz yüze geçen zamanı ise bilgiyi uygulama ve çeşitli üst düzey bilişsel etkinlikler için kullanabilmektedir. Tıp eğitiminde başarılı ters yüz sınıf uygulamaları da alan yazında yer almaktadır.

Anahtar kelimeler: Ters yüz sınıf, aktif öğrenim, öğrenci merkezli öğretim

\section{GiRiş}

Ters yüz sınıf en temel haliyle tanımlanırsa derste yapılan ders etkinliklerinin internet üzerinden yapılması, evde yapılan ev ödevi uygulamalarının ise sınıfta yapılmasıdır. Çıkış noktası ise dersi dinlemek pasif bir işlem olup, öğrenci ders videoları ile kendi kendine dersi izleyip öğrenebileceği fikridir. Derste öğrenilenlerin uygulaması olan ev ödevi ve benzeri etkinlikler ise öğrencinin öğretmene daha çok intiyaç duyabileceği etkinlikler olup, sınıfta bir öğretmen rehberliğinde yapılmasının daha etkin öğrenmeyi sağlamasıdır. Aslında evde dersi çalışın, derste tartışalım düşüncesinin çağdaş bir uygulamasıdır denilebilir. Ama tabii ki güncel uygulama bu kadar basit olmadığı gibi kazanımları da çok daha fazladır.

Ters yüz sınıf 2007 yılında Amerika Birleşik Devletlerinde iki lise kimya öğretmeni tarafından başlatılmıştır (1). Başlangıçta öğretmenler spor ve benzeri aktiviteler nedeniyle dersleri kaçıran çocuklara nasıl yardımcı oluruz diye düşünmüşlerdir. Bu amaçla anlatılan kimya derslerini, kısa videolar halinde çekerek, dersleri kaçıran öğrencilerin izlemesi için internet orta-

\section{Abstract}

The flipped classroom is a relatively new learning approach that focuses on learner-centered instruction. In this method, online lectures take place outside classrooms, and classrooms are used for active learning. Teachers could use the face-to-face classroom time for training students to apply their knowledge and skills to a range of activities using higher-order thinking. The successful implementation of flipped learning in medical education has been reported in literature.

Keywords: Flipped classroom, inverted classroom, active learning, learner-centered instruction

mına yüklemişlerdir. Sonraki süreçte bu videoları sadece dersleri izleyemeyen öğrencilerin değil, dersi izlediği halde anlamayan öğrencilerinde izlediğini fark etmişlerdir. Zamanla video derslerin ünü yayılmış, diğer liselerdeki öğrenciler, hatta vekil ve acemi öğretmenlerde video dersleri izlemeye başlamışlardır. Bu tecrübe sonrası dersi izledikleri halde ev ödevlerindeki uygulamayı yapamayan öğrencilere yardım etmeyi planlarken "ters yüz sınıf" fikri ortaya çıkıyor. Öğrencilerin video derslerden kendi kendilerine öğrendiklerini gören öğretmenlerimiz sonraki aşamada ise video derslerin izlenmesini ödev olarak verip, ödev olan uygulamaları ise ders saatinde yapmaya başlamışlardır. Böylece ters yüz sınıf modeli ortaya çıkmıştır. Tüm dersleri videoya alıp ev ödevi olarak izlenmesini sağlarken, sınıf içi etkinliklerde ise ya laboratuvar uygulamaları ya da ev ödevi etkinliği olan soru çözme benzeri uygulamaları yapmaya başlamışlardır. Bu süreçlerde, öğrencinin tam intiyacı olduğunda öğretmenler öğrencilerin yanında yer almışlardır. Bergmann ve Sams uygulamanın çok çeşitli avantajlarını gözlemlemişlerdir (1). Örneğin dersi izleme hızı daha yavaş olan öğrenciler için video dersleri tekrar tekrar izlemek büyük avantaj 
sağlamıştır. Farklı programdan gelen ya da ana dili Ingilizce olmayan öğrenciler için de tüm ders videoları hazır kaynak oluşturmuştur. Ters yüz sınıf modeli kısa zamanda hızla popülerlik kazanmıştır. Sonraki yıllarda bu model gerek orta öğretim programlarında, gerekse de yükseköğrenimde hızla kabul görerek uygulanmaya başlanmıştır. Doğal olarak bu uygulamalar ilköğretimdeki uygulamanın aynısı olmayıp, her programın intiyaçlarına göre değişmektedir.

Ters yüz sınıfta öğrenciler ders içeriğini, evde çevrim içi kaynakları kullanarak öğrenirken, sınıf içi ders saatlerini öğretmen rehberliğinde tartışma, problem çözme benzeri aktif öğrenme yöntemleri kullanılan aktivitelerle değerlendirmektedirler. Öğretmen ve öğrencinin rolleri değişmiştir. Geleneksel sınıf modelinde her şeyi bilen ve ders anlatan öğretmen, ters yüz sınıf modelinde artık sınıfta ders anlatan rolü yerine öğrencilerin yanında yer alıp öğrenmede bireysel rehberlik yapan kişiler olmaktadırlar. Diğer taraftan öğrenme sorumluluğu ise öğrenciye geçmiştir.

Bir ters yüz sınıf uygulaması iki kısımdan oluşmaktadır. Birincisi okul dışında öğrencinin kendi başına izleyip öğreneceği sıklıkla kullanıldığı üzere video derslerin yer aldığı kısımdır. Ikincisi ise sınıfta yapılan aktif öğrenme yöntemlerinin kullanıldığı öğrenme etkinlikleridir.

\section{VIDEO DERSLER NASIL HAZIRLANMALIDIR?}

Başarılı bir ters yüz sınıf uygulaması için ön hazırlık yapılması gerekmektedir. Video dersleri hazırlanması da önceden yapılması gereken hazırlıklardan birisidir. Ancak bu noktada dikkat edilmesi gereken video derslerin normal ders sürecinden farklı olduğudur. Normal sınıf derslerini videoya çekerek video ders yapılması başarısızlıkla sonuçlanacaktır. Çünkü yalnız başına, uzun bir süre çevrim içi ders izlemek kolay değildir. Bu tür bir video dersin kolayca izlenmesi için önerilen en uzun süre ortalama 10-15 dakikadır. Dolayısıyla bu ders videolarının yaklaşık 10-15dk'lık mini videolar olması gerekmektedir. Bu 10-15dk bitiminde ise bir kaç soru veya bir vaka tartışması öğrencinin aktif olarak katılmasını sağlayacaktır. Bu tür bir videoda eğer slayt kullanılıyorsa, slaytın bir kısmında öğretmenin ders anlatan yüzünün yer alabildiği Camtasia ${ }^{\circledR}$ (TechSmith, Michigan, ABD) veya benzeri bir programın (Screenflow $\AA$; Telestreem, Nevada City, ABD, Profcast $\AA$; Humble Daisy Inc., Michigan ABD) kullanılması canlı ders etkisi yapacaktır. Bu tür videoları hazırlamak biraz zaman alsa bile uzun dönemde, içeriğinde çok büyük değişiklikler olmadığı sürece tekrar tekrar kullanılabilir.

\section{ÖĞRENCILER VIDEO DERSLERi IZLEMEYEBILIRLER MI?}

Öğrenme sorumluluğuna alan öğrenciler video dersleri mutlaka izleyeceklerdir. Zaten sınıf içi uygulamalara katılabilmeleri için derslere çalışıp gelmeleri gerekmektedir. 10-15 dk'lık mini videolar hazırlanması, videoların bitiminde veya içinde, öğrencinin cevaplaması için sunumla ilgili sorulara yer verilmesi video derslerin izlenmesini sağlamak için faydalı olacaktır. Kimi uygulamalarda ise öğrencinin kendi kendini değerlendirdiği çevrim içi sınavlar yapılabilir. Bu tür sınavlar sınıf içi etkinliklerin başında da yapılabilir. Öğrencilerin anlamadıkları noktalar bu sınav sonuçlarına göre de saptanabilir ve sınıf etkinliklerinin başında tartışılabilir.

\section{DERS SAATLERI NASIL DEĞERLENDIRILMELIDIR?}

Öğrenciler dersi evde izleyip öğreniyorlarsa ders saatinde neler yapılabilir? Uygulamadaki en önemli soru budur. Özelikle ülkemizdeki geleneksel klinik eğitim sürecinde sıklıkla rastlandığı üzere sadece didaktik ders anlatan eğitmenler bu noktada şaşırabilirler. Öğrenciler teorik olarak bilgiye erişmiş yani derste öğrenmeleri gerekeni öğrenmiş geleceklerdir. Ders saatleri öğrencilerin evde izleyip anlamadıkları noktaları sormalarıyla başlar. Anlaşımayan noktaların tartışılmasını takiben, video derslerin izlenmesini sağlamak için ders içeriklerinden oluşan küçük sınavlar yapılabilir. Bunu takiben orta öğrenimde genelde eve ödev olarak verilen soru çözme etkinlikleri yapılmaktadır. Ya da fen derslerinde öğrenciler öğrendikleri dersle ilgili deney yapabilirler. Tıp fakültesinde ise video derslerde anlaşılmayan noktaların tartışılmasını takiben, proble-

Tablo 1. Bloom'un bilgi ve zihinsel becerilerin gelişimini gösteren taksonomisi

Değerlendirme: Bireyler karar verebilir ve yargıya varabilir.

Sentez: Parçaları birleştirerek bütüne ulaşmak olarak adlandırılabilir.

Analiz: Elde olan verilerden mantıklı çıkarımlar yaparak çözmek, sonuç odaklı inceleme işlemi yapmaktır.

Uygulama: Önceden edinilen bir bilgiyi yepyeni durumlarda kullanabilmektir.

Kavrama: Yorumlama, başka sözcüklerle tanımlama, örnekler verebilme ve karşılaştırma yapabilmesi olarak özetlenebilir.

Bilgi: Ezber olarak da nitelendirdiğimiz bilgileri içermektedir. Önceden edinilen bilginin hatırlanmasıdır. 
me dayalı öğrenme oturumları, takım temelli öğrenme etkinlikleri gibi aktif öğrenme yöntemlerine dayalı etkinlikler planlanabilir (2). Öğrencileri Bloom taksonomisinde üst basamaklara çıkaran vaka tartışmaları en uygun uygulamalar olacaktır (Tablo 1) (3). Bloom'a göre bilişsel gelişim seviyeleri en basitten en karmaşığa doğru altı seviyeden oluşmaktadır. Bilişsel öğrenme en aşağıdan yukarıya doğru ilerler. Üst düzey bilişsel beceriler taksonomide yukarıya doğru çıktıkça yer almaktadır. $\mathrm{Bu}$ basamaklara ulaşmak için sadece ders anlatma yeterli olmamaktadır. Üst düzey bilişsel becerilere ulaşmak için problem çözme, vaka tartışmaları gibi bilgiyi kullanma ve uygulamaya yönelik aktif öğrenme etkinlikleri gerekir. Tıp eğitiminde de nihai amaç sadece derste anlatılanı bilen ve tekrarlayan değil, Bloom taksonomisinin yukarı kısımlarında yer alan üst düzey bilişsel becerilere ulaşmamızdır. Ters yüz sınıf modeli dersi öğrenip gelen yani ilk basamağı geçen öğrencilerle öğretmen rehberliğinde yukarı basamaklardaki etkinlikler yapılmasına olanak sağlamaktadır.

Öğrenciler her vakayı öğretim üyesi rehberliğinde tartışabilirler. Bu vaka tartışma saatleri dişında ise geleneksel tıp eğitiminde olduğu gibi, staj yapan öğrenciler poliklinik hizmetleri, vizitler, ameliyathane gibi hasta bakım hizmeti sürecindeki etkinlikler devam edecektir. Bütün dersleri önceden öğrenip geldikleri için öğrenciler bu uygulama sürecine daha bilinçli olarak katılacaklardır. Aktif öğrenme etkinlikleri hasta bakım hizmeti verilen saatlerin dışında yapılırsa da öğrencilere daha çok hasta ile karşılaşma ve uygulama yapma fırsatları sağlanmış olacaktır.

\section{TERS YÜZ SINIF UYGULAMASINDA KARŞILAŞILACAK OLASI PROBLEMLER}

1. Çok yoğun video ders hazırlanması olası sorunlardan birisidir. Örneğin normal programdaki 40 dk'lık dersin yerine saatlerce ders hazırlanması uygulamayı bozacaktır. Normal de programda yer alan tek bir ders saati için saatlerce video dersler hazırlanması uygulamayı bozacaktır.

2. Video dersler yerine başka çözümler var mıdır?

Dersin yerini tutabilecek en ideal uygulama ve en motive edici olan mini ders videoları hazırlanmasıdır. Ama alan yazında ders notları verilmesi ya da interaktif ders sunumlarının da bu amaçla kullanıldığı bildirilmektedir. Eğer video çekilemiyorsa powerpoint ${ }^{\circledR}$ (Microsoft, Albequerque, ABD) sunumları da seslendirilebilir. Kendi uygulamalarımızdan gördüğümüz "dijital yerli" olan öğrencilerin kısa videoları ve internet üzerinde bile interaktif uygulamaları arzuladıklarıdır.

3. Dersleri izleyip öğrendiklerine göre diğer zamanlar da öğrencilerin başıboş bir şekilde bırakılması en olası tehlikelerden birisidir. Hizmet baskısının yoğun olduğu tıp fakültesi hastanelerinde, geleneksel eğitimdeki sadece teorik ders anlatarak eğitim veren ve bu vesileyle bu ders verme görevini de bırakan öğretim üyeleri sadece hizmete yönelip eğitim sürecini boşlayabilirler. Bu durumda yönetim tarafından öğretim üyeleri için hizmet içi eğitimle aktif eğitim teknikleri öğretilmesi ya da eğitimi programlama aşamasında destek olunması gerekebilir.

4. Bu videoları öğrencilere internet üzerinden nasıl sunmalıyız?

İnternet üzerinden eğitim amaçlı planlanmış öğrenme platformları (virtual learning environments-VLEs, learning management systems-LMSs) bu amaçla tasarlanmış olup kolayca kullanılabilmesi için çok çeşitli araçlara sahiptir. Bu platformlar video yükleyip, sınavlar yapmak gibi etkinlikler için hazır ortamlardır. Videoları kimlerin ne kadar izledikleri gibi çok sayıda istatistik veri kolayca elde edilebilir. Bu platformlar arasında Moddle ${ }^{\circ}$ (Moodle Pty, Pert, Australia)ülkemizdeki hemen hemen her üniversitede Eğitim Destek Sistemi adı altında mevcut bir program olup, bu tür amaçlarla kullanılabilir. Eğer bir üniversitede çalışıyorsanız bu konuyu bilgi işlem dairesine başvurarak öğrenebilirsiniz. Okula ait web sitesi de ya da Youtube $\AA$ gibi sitelerde ders videoları yüklemek için uygundurlar. EDpuzzle $®$ (Palo Alto, ABD) daha interaktif video dersler için olanaklar sağlarken, dersi izleyen öğrenciler ve etkinlikler için istatistik veri de sağlamaktadır. Bu makalede örnek olabilecek birkaç program belirtilmiştir. Benzeri amaçlarla kullanılmak üzere yapılmış ücretli veya ücretsiz çok sayıda program bulunabilir. Unutulmaması gereken, internet uygulamalarında teknik destek gerekebileceğidir.

5. Ters yüz sınıf uygulamasında sadece eğiticiler değil, geleneksel sınıf modelinde yetişmiş olan öğrenciler de şaşırabilir ve mutsuz olabilirler. Sınıfa gelmeden çalışma gerektirmesi, öğrenciler tarafından kabulü zorlaştırabilir. Ancak başarılı bir uygulama gerçekleştirildiğinde öğrenciler hızla uyum sağlayacak ve mutlu olacaklardır.

6. Her öğrenci internete ulaşamayabilir. Günümüzde internete ulaşmak giderek daha kolaylaşmakta ve yaygınlaşmaktadır. Bu tür imkanı olmayan öğrenciler için bilgisayar ve internet imkanları sağlanmalıdır.

7. Eğitim program saatlerinde de öğrencilere video dersleri izleyebilecekleri zaman aralıkları ayırmak gerekir.

\section{TERS YÜZ SINIFIN AVANTAJLARI NELERDIR?}

Çok çeşitli avantajlarından bahsetmek mümkündür. Öğrenciler tüm dersleri istedikleri zaman istedikleri 
kadar izleyebilirler. Farklı öğrenme hızına sahip öğrenciler için dersi kendi hızında tekrar tekrar izleme şansı yaratır. Bu şekilde kendi kendine öğrenme alışkanlığı da kazandırılır. Sınıf içi aktiviteler ise öğrenci öğretmen iletişimini artırır. Öğretmen öğrenme konusunda zorluk çeken öğrencilere daha fazla zaman ayırabilir. Öğretmenin öğrencilerini daha yakından tanıma imkanı sağlar. Küçük grup çalışmaları gibi sınıfta öğrencilerin birlikte yapacakları aktivitelerle öğrencilerin birlikte çalışma ve iletişim kurma şansları artacaktır. Sınıfın kapılarını herkese açarak eğitim sürecinin şeffaflaşmasını sağlar (1).

Alan yazına bakıldığında yüksek öğrenim uygulamalarıyla ilgili her makalenin ters yüz sınıfın farklı avantajlarını vurguladığı görülmektedir. Halk sağlığı uygulamasında öğrenciler süreci "pozitif öğrenme deneyimi" olarak tanımlamışlardır (4). Beslenme dersinde uygulandığında öğrenciler ters yüz sınıf uygulamasını daha çok tercih etmişler ve gerek öğrenciler ve gerekse de eğitmenler tarafından başarıyla kabul görmüştür (5). Kadın doğum staj uygulamasında teknolojiyi kullanarak öğrencilerin zamanını daha verimli kullandıkları ve öğrencilerin çevrim içi didaktik dersleri de beğendiklerini rapor etmişlerdir (6). Mezuniyet öncesi tıp eğitiminde ilk yılın tümünde uygulamışlar ve öğrenci ve eğiticiler tarafından kabul gördüğünü belirtmişlerdir (7). Ayrıca öğrenme süreci her öğrenciye göre kişiselleşmesine olanak sağlar (8). Öğrencinin merkezli bir uygulama olup, öz denetimli öğrenme becerisini geliştirerek yaşam boyu öğrenme alışkanlığı kazandıır. Tıp eğitiminde de yeni bir uygulama şekli olarak ters yüz sınıf uygulama sonuçları giderek daha da artan şekilde alan yazında yer almaktadır. Her araştırmada kendi uygulama amacına yönelik avantaj veya dezavantajlar rapor edilmektedir.

\section{TERS YÜZ SINIF UYGULAMALARI}

Alan yazında tıp eğitiminde ters yüz sınıf uygulaması ilgili çeşitli sonuçlara rastlanmaktadır. Bunlar genelde tüm eğitim programı uygulamasından çok belli stajlar ve kursları içermektedir. Bu model mezuniyet öncesi ilk eğitim yıllarında didaktik dersler yerine küçük gruplarda probleme dayalı öğrenme oturumları, tartışmalar veya daha çok laboratuvar uygulaması yapmaya olanak sağlayabilir. Artan öğrenci sayısı karşısında öğretim üyeleri saatlerce ders anlatmak yerine, bu saatleri daha küçük grup öğrencilerle yüz yüze etkinliklerle değerlendirebilirler. Klinik eğitimde teorik bilgiye öğrenip gelen öğrencilerle daha üst düzey uygulamalar yapılabilir. Ters yüz sınıf modeli "uzmanlık okulları" için çok iyi bir örnek olabilir. Tüm uzmanlık öğrencilerini toplayıp saatlerce didaktik ders anlatmak yerine bu kısmın kısa videolarla sunulması, kalabalık öğrenci gruplarıyla bir araya gelinen kısmında ise küçük grup çalışmaları, vaka tartışmaları gibi aktif uygulamalar yapılabilir. Böylece hem eğitim süreci daha eğlenceli hale gelecek, hem de öğrenciler bilişsel olarak daha üst seviyeye ulaşmış olacaklardır.

\section{TERS YÜZ SINIF MODELI ÜLKEMIZ IÇIN UYGUN MUDUR?}

Ülkemizde ilköğretimden itibaren daha çok öğretmen merkezli öğrenme yöntemlerinin kullanıldığı, bu nedenle ülkemiz öğrencilerinin bu tür bir uygulamaya uyum sağlayamayacağı ön yargısı olabilir. Bu tür bir algı Asya ülkelerinde de mevcut olduğu düşüncesiyle bu ülkelerdeki ters yüz sınıf uygulamalarının sonuçları incelendiğinde öğrencilerin başarıyla uyum sağladıkları görülmüştür (9). Ülkemizde de eğitim süreci yıllar içinde çok değişmiş ve aktif öğrenme metodları artık ilköğretimden itibaren yaygın kullanılmaktadır. İnternet üzerinden kısa bir tarama yapıldığında da görülmektedir ki ülkemizde de ters yüz sınıf yüksek öğrenimde tıp eğitimi dışında kullanılmaktadır. Ülkemizdeki tıp fakültelerine bakıldığında mezuniyet öncesi eğitim akreditasyon süreci, tıp eğitimi anabilim dallarının yaygınlaşması ve tıp fakültelerindeki probleme dayalı öğrenme gibi aktif öğrenme yöntemlerinin kabul görmesi nedeniyle ülkemiz tıp eğitimi programlarında da giderek daha çağdaş yöntemler kullanıldığı söyleyebiliriz. Dolayısıyla ülkemiz tıp eğitiminde ters yüz sınıf modeli de başarıyla uygulanabilir.

\section{SONUÇ}

Gelişen teknolojiyle birlikte eğitim uygulamaları da değişmektedir. Ters yüz sınıf bunun iyi bir örneğidir. Nispeten karşılaşabilecek teknik zorluklar göz ardı edilirse uygulama kolaylığı açısından gelecekte de çok yaygınlaşacaktır.

\section{KAYNAKLAR}

1. Bergmann J, Sams A. Flip Your Classroom Reach Every Student in Every Class Every Day 1st ed. Washington: Iste; 2012.

2. Smith JS. Active learning strategies in the physician assistant classroom--the critical piece to a successful flipped classroom. J Physician Assist Educ 2014;25:46-9. [CrossRef]

3. Uzunboylu $\mathrm{H}$, Hürsen Ç. Öğretim ilke ve yöntemleri 1. Baskı Ankara: PEGEM akademi; 2010. p. 30-2.

4. Galway LP, Corbett KK, Takaro TK, et al. A novel integration of online and flipped classroom instructional 
models in public health higher education. BMC Med Educ 2014;14:181. [CrossRef]

5. Gilboy MB, Heinerichs S, Pazzaglia G. Enhancing student engagement using the flipped classroom. J Nutr Educ Behav 2015;47:109-14. [CrossRef]

6. Morgan H, McLean K, Chapman C, et al. The flipped classroom for medical students. Clin Teach. 2015;12:155-60. [CrossRef]
7. Gillois P, Bosson JL, Genty C, et al. The impacts of blended learning design in first year medical studies. Stud Health Technol Inform 2015;210:607-11.

8. Kurup V, Hersey D. The changing landscape of anesthesia education: is Flipped Classroom the answer? Curr Opin Anaesthesiol 2013;26:726-31. [CrossRef]

9. Joanne CSM, Lateef F. The flipped classroom: Viewpoints in Asian Universities. Education in medicine journal 2014;6:20-6. 